\title{
Role of Iron Phthalocyanine Coordination in Catecholamines Detection
}

\author{
Cibely S. Martin, Rafael J. G. Rubira, Jaqueline N. Silva (1) and Priscila Aléssio * (])
}

Citation: Martin, C.S.; Rubira, R.J.G.; Silva, J.N.; Aléssio, P. Role of Iron Phthalocyanine Coordination in Catecholamines Detection. Surfaces 2021, 4, 323-335. https://doi.org/ 10.3390 /surfaces 4040027

Academic Editor: Gaetano Granozzi

Received: 9 November 2021

Accepted: 8 December 2021

Published: 12 December 2021

Publisher's Note: MDPI stays neutral with regard to jurisdictional claims in published maps and institutional affiliations.

Copyright: (c) 2021 by the authors. Licensee MDPI, Basel, Switzerland. This article is an open access article distributed under the terms and conditions of the Creative Commons Attribution (CC BY) license (https:// creativecommons.org/licenses/by/ $4.0 /)$.
School of Technology and Applied Sciences, São Paulo State University (UNESP),

Presidente Prudente 19060-080, SP, Brazil; cibely.martin@unesp.br (C.S.M.); rafael.rubira@unesp.br (R.J.G.R.); jaqueline.nascimento@unesp.br (J.N.S.)

* Correspondence: priscila.alessio@unesp.br

Abstract: Catecholamines are an important class of neurotransmitters responsible for regularizing, controlling, and treating neural diseases. Based on control and diseases treatment, the development of methodology and dives to sensing is a promissory technology area. This work evaluated the role of iron phthalocyanine coordination $(\mathrm{FePc})$ with the specific groups from catecholamine molecules (L-dopa, dopamine, epinephrine, and the amino acid tyrosine) and the effect of this coordination on electrochemical behavior. The in situ coordination analysis was performed through isotherms $\pi$-A of FePc Langmuir films in the absence and presence of catecholamines. The $\pi$-A isotherm indicates a strong interaction between FePc monolayer and L-Dopa and DA, which present a catechol group and a side chain with a protonated amino group $\left(-\mathrm{NH}_{3}{ }^{+}\right)$. These strong interactions with catechol and amine groups were confirmed by characterization at the molecular level using the surface-enhanced Raman spectroscopy (SERS) from a Langmuir-Schaefer monolayer deposited onto Ag surfaces. The electrochemical measurements present a similar tendency, with lower oxidation potential observed to DA $>$ L-Dopa $>$ Ep. The results corroborate that the coordination of the analyte on the electron mediator surface plays an essential role in an electrochemical sensing application. The FePc LS film was applied as a sensor in tablet drug samples, showing a uniformity of content of $96 \%$ for detecting active compounds present in the L-Dopa drug samples.

Keywords: catecholamines; iron coordination; phthalocyanines; electrochemical sensing

\section{Introduction}

Catecholamines are a group of similar neurotransmitter hormones produced in the adrenal medulla. The main catecholamines are norepinephrine, epinephrine, and dopamine. Usually, catecholamines and their metabolites are present in the body in small variable amounts, which only increase considerably during and soon after physical or emotional stress [1]. Studies in humans have implicated prefrontal catecholamines in the control of cognitive functions. Many of these cognitive functions are disrupted in mental disorders. Therefore, an imbalance in prefrontal catecholamines has been associated with these mental illnesses, such as Parkinson's disease [2], Alzheimer's [3], and schizophrenia [4]. Thus, it is crucial to develop sensitive and selective techniques or methodologies to determine neurotransmitters in biological relevant concentrations to provide a means of diagnosis and possible treatment of the related neurological diseases.

Because iron chelators and catecholamines form complexes, the study of iron in clinical practice as a protecting agent against catecholamine-induced oxidative injury is reported [5]. Oni and Nyokong [6] detailed the interaction between iron (II) tetrasulfophthalocyanine and serotonin and dopamine neurotransmitters. They prove that the interaction results in the coordination of dopamine and serotonin to [FeTSPc $]^{4-}$, followed by internal electron transfer and the formation of $\left[\left(\mathrm{DA}^{+}\right) \mathrm{FeITSPc}\right]^{4-}$ and $\left[(5-\mathrm{HT}+) \mathrm{Fe}^{\mathrm{I}} \mathrm{TSPC}^{4-}\right.$ complexes, respectively [6]. In the same way, the use of iron-based nanostructures $[7,8]$, metallopor- 
phyrin $[9,10]$, and metallophthalocyanines [11-13] to detect catecholamines is widely found in the literature.

Here, we report taking advantage of the Fe-catecholamines complex formation to optimize the catecholamines detection and overcome the interference difficulty once the structures of these molecules are quite similar. For that, we use the techniques of SurfaceEnhanced Raman Scattering allied to cyclic voltammetry and data projection.

\section{Materials and Methods}

\subsection{Reagents and Solutions}

Iron (II) phthalocyanine (FePc, Kodak, MW $=568.38 \mathrm{~g} / \mathrm{mol}$ ) was applied as coordination material in Langmuir films, SERS, and electrochemical analysis. The evaluation of coordination and interaction with the FePc molecules were carried out using the amino acid L-tyrosine (Ty, Sigma Aldrich) and the catecholamines: 3,4-dihydroxy-L-phenylalanine (L-Dopa, Sigma), dopamine hydrochloride (DA, Fluka), and (-)Epinephrine (Ep, Sigma). Potassium chloride ( $\mathrm{KCl}$, Sigma Aldrich) was used as a supporting electrolyte in the electrochemical measurements. All aqueous solutions were prepared with a Millipore Milli-Q system (resistivity $\geq 18 \mathrm{M} \Omega . c m$ ).

\subsection{Langmuir Films}

The Langmuir films were grown using a KSV Langmuir trough model 2000 (Biolin Scientific) by spreading $500 \mu \mathrm{L}$ of a $0.5 \mathrm{mg} / \mathrm{mL}$ FePc solution dissolved in DCM, with symmetric compression at $10 \mathrm{~mm} / \mathrm{min}$. The FePc Langmuir films were formed in the absence and presence of catecholamines at $10^{-5}, 10^{-4}$, and $10^{-3} \mathrm{~mol} / \mathrm{L}$ and analyzed through $\pi$-A isotherm.

\subsection{SERS Analysis}

Langmuir monolayer of $\mathrm{FePc}$ in the absence and presence of catecholamines (at $10^{-4} \mathrm{~mol} / \mathrm{L}$ ) was deposited onto Ag substrate $(5 \mathrm{~nm}$ of Ag thickness obtained from physical vapor deposition-PVD) at $24 \mathrm{mN} / \mathrm{m}$ by Langmuir-Schaefer (LS) deposition, which was carried out using the horizontal contact of the substrate surface to the air/water interface (manually). The SERS spectra were collected by a spectrograph Renishaw inVia, with a $633 \mathrm{~nm}$ laser line $(1800 \mathrm{l} / \mathrm{mm})$ coupled to a Leica optical microscope (objective lens of $50 \times$ ).

The SERS spectrum of FePc and FePc/catecholamine LS films were also analyzed by using Interactive Document Mapping (IDMAP) [please, insert here the reference "Rosane Minghim, Fernando Vieira Paulovich, and Alneu de Andrade Lopes, Content-based Text Mapping Using Multi-Dimensional Projections for Exploration of Document Collections, Proceedings of SPIE-IS\&T Electronic Imaging-Visualization and Data Analysis-VDA 2006], whose function is defined as follows:

$$
S_{I D M A P}=\frac{\delta\left(x_{i}, x_{j}\right)-\delta_{\min }}{\delta_{\max }-\delta_{\min }}-d\left(y_{i}, y_{j}\right)
$$

where $\delta$ and $d$ are the distance functions defined for the original SERS spectra $\left(\mathrm{X}=\left\{x_{1}, x_{2}\right.\right.$, $\left.\ldots x_{\mathrm{n}}\right\}$ and projected spaces $\left(\mathrm{Y}=y_{1}, y_{2} \ldots y_{\mathrm{n}}\right)$ on the graphical markers (2D plot). The $\delta\left(x_{\mathrm{i}}, x_{\mathrm{j}}\right)$ is defined as the distance between two data instances $\mathrm{i}$ and $\mathrm{j}$; the $\delta_{\max }$ and $\delta_{\min }$ are the maximum and minimum distances between the samples, respectively. The $d\left(y_{i}, y_{j}\right)$ is the distance function on the projected plane. In this case, the samples are each SERS spectra collected through the SERS substrate for FePc and FePc/catecholamine LS films.

\subsection{Catecholamines Detection by Cyclic Voltammetry}

The electrochemical measurements were performed using 20 LS layers of FePc onto ITO electrodes (c.a $1 \mathrm{~cm}^{2}$ geometric area). The cyclic voltammetry was carried out in a $0.1 \mathrm{~mol} / \mathrm{L} \mathrm{KCl}$ aqueous solution of $(\mathrm{pH} \sim 5.6)$ as a supporting electrolyte, to which $1.2 \times 10^{-4} \mathrm{~mol} / \mathrm{L}$ of each catecholamine was added to study catecholamine oxidation. All electrochemical analyses were performed in an electrochemical cell with three-electrode: 
$\mathrm{Ag} / \mathrm{AgCl}$ as a reference electrode, $\mathrm{Pt}$ wire as a counter electrode, and ITO modified as a working electrode, applying a potential range of -1 to $+1 \mathrm{~V}$ with a $25 \mathrm{mV} / \mathrm{s}$ of scan rate.

The FePc LS films were evaluated as L-dopa sensors in pharmaceutical drug samples. The sample preparation was based on a drug tablet that was ground up, which was transferred to an Erlenmeyer flask and to which was added approximately $50 \mathrm{~mL}$ of cold ultrapure water. The solution, with a reddish color, was kept under constant agitation for $10 \mathrm{~min}$ in an ice bath. Then, the solution was filtered and placed in a volumetric flask, and the volume was adjusted to $100 \mathrm{~mL}$ with cold ultrapure water. The filtration removed the excipients in suspension. The solution was kept in an ice bath, and the electrochemical measurements were performed one hour after preparing the drug sample.

\section{Results and Discussion}

In general, free iron can be complex to catechol groups providing coordination through oxygen atoms [14]. The MPc also showed interesting coordination with the oxygen [15] and nitrogen atom $[16,17]$. Thus, we evaluated the possible coordination of some catecholamine, which has both catechol and amine groups in the structure, with the FePc. The interaction was assessed by forming FePc Langmuir films in the absence and presence of catecholamine: L-Dopa, DA, and Ep. Analysis in the presence of Ty (a catecholamine precursor, was also evaluated to reinforce the structure effect on the FePc coordination. The FePc interaction with different concentrations of catecholamine was evaluated through $\pi$-A isotherms (Figure 1).
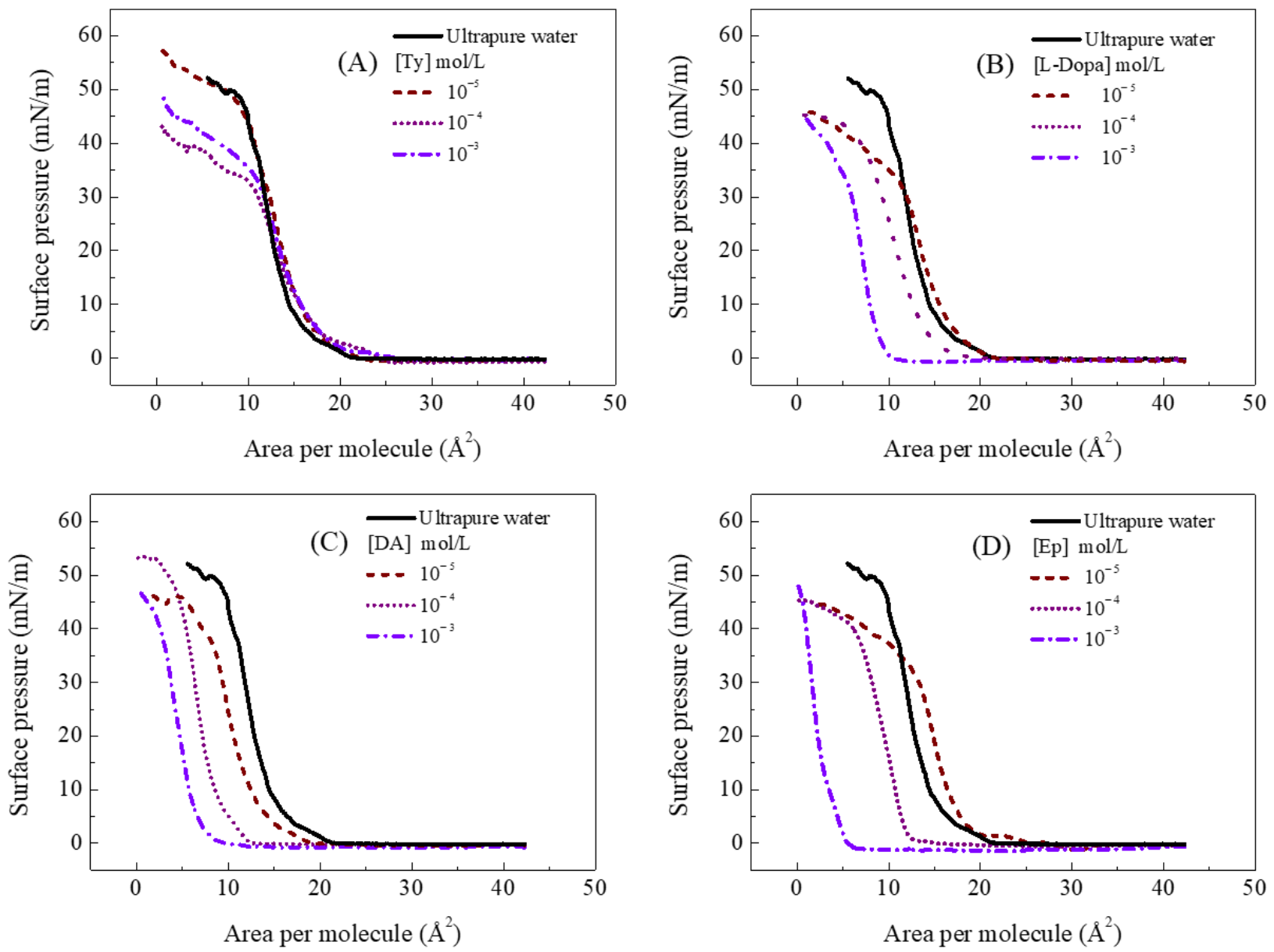

Figure 1. $\pi-\mathrm{A}$ isotherms for Langmuir films at $23{ }^{\circ} \mathrm{C}$ in ultrapure water, (A) tyrosine, (B) L-Dopa, (C) dopamine, and (D) epinephrine subphase. 
The $\pi$-A isotherms of FePc in the aqueous subphase showed a characteristic extrapolated area of c.a $16 \AA^{2}[18,19]$, which indicates some packing degree even in ultrapure water [19]. In the presence of Ty and catecholamine, changes in the collapse range and a shift on the extrapolated area were observed (Figure 2), respectively. Here, it is important to note that not all molecules can show a charge in an aqueous solution according to subphase $\mathrm{pH}$ (Figure 2), directly influencing the interaction with the FePc monolayer.
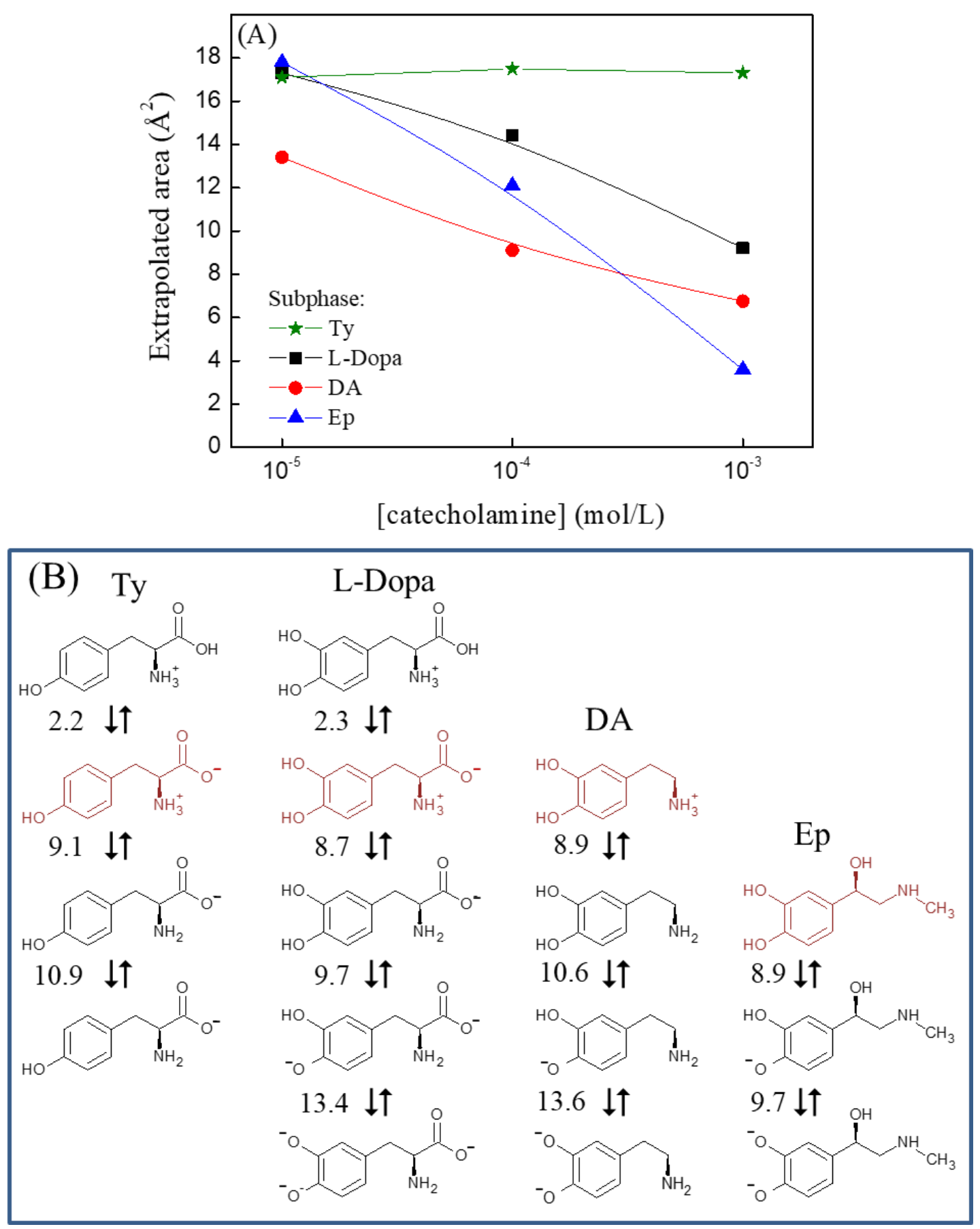

Figure 2. (A) Extrapolated area in the function of Ty and catecholamine concentration used in the subphase. The extrapolated area was obtained using the fit linear transverse isotherm range shown in Figure 1. (B) Chemical structure of Ty and catecholamine (L-Dopa, DA, and Ep) considering the $\mathrm{pKa}$ equilibrium (red color represents the majority species present in the $\mathrm{pH}$ of this work, $\mathrm{pH}$ c.a 5.6). 
Figure $1 \mathrm{~A}$ shows a slight shift (to c.a $17 \AA^{2}$ ) to the FePc isotherm in the Ty subphase compared to the ultrapure water subphase. For concentrations of $10^{-3}$ and $10^{-4} \mathrm{~mol} / \mathrm{L}$, there is a decrease in the collapse pressure of the FePc. Reductions in the collapse pressure can be ascribed to the organized reorganization of monolayer forming a tridimensional structure through a horizontal break [20]. The decreases in collapse pressure can also be observed during the in-situ complexation of organic ligand and metal ions present in the subphase [21]. According to Phan, Lee, and Shin [20], experimental conditions, i.e., temperature, ion presence, subphase $\mathrm{pH}$, and compression rate, can also alter the collapse pressure.

A similar change in the collapse range of the $\pi$-A isotherm was also observed in the FePc monolayer at the L-Dopa subphase. Comparing the chemical structure of Ty and L-Dopa, both molecules have the same side chain and a zwitterion charge, which suggests that interaction with the side chain promotes collapse changes. On the other hand, the FePc $\pi$-A isotherms in the presence of $10^{-3}$ and $10^{-4} \mathrm{~mol} / \mathrm{L}$ L-Dopa in the subphase showed displacements of 6.8 and $1.6 \AA^{2}$ to the smaller extrapolated area, respectively. The lower concentration of L-Dopa $\left(10^{-5} \mathrm{~mol} / \mathrm{L}\right)$ causes similar displacements and collapse pressure observed in the presence of Ty. The displacement to the smaller extrapolated area can be ascribed to loss of interface material to subphase and the increases of the packing degree of the molecules present at the interface [18]. Considering that FePc showed a high packing degree through $\pi-\pi$ interaction, the L-Dopa can promote increases of this packing degree. In this case, the interaction can be ascribed to the coordination of FePc with the catechol group. Indeed, the Fe atom shows interaction with the catechol group through the formation of the Fe-O bond [22]. Moreover, catecholamine like L-Dopa, DA, and Ep can undergo oxidation in solution, resulting in indoline-like cyclodopa (cyclic species) and auto-polymerization [23-25]. Thus, the formation of this species at $10^{-3} \mathrm{~mol} / \mathrm{L}$ of catecholamines at subphases can also occur, and the catechol group also influences the FePc packing from cyclic species.

The FePc coordination through the catechol group was reinforced by $\pi$-A isotherm of FePc obtained at the DA subphase, once it also showed a displacement to a smaller area and in L-Dopa subphase. $\pi$-A isotherm showed the displacement of 2.6, 6.9, and $9.2 \AA^{2}$ for DA concentrations of the $10^{-5}, 10^{-4}$, and $10^{-3} \mathrm{~mol} / \mathrm{L}$, respectively (Figure 1C). The displacement observed for FePc $\pi$-A isotherms was higher for DA than L-Dopa, reinforcing that the FePc molecules' packing degree at the interface (monolayer) is promoted by the catechol group. The DA also has a $-\mathrm{NH}_{3}{ }^{+}$group in the side chain, which can also interact with the Fe center from the FePc molecule [16], increasing the DA interaction with FePc molecules. The DA subphase did not promote changes in the collapse range of the $\pi$-A isotherm.

The $\pi$-A isotherms thus indicate that the deprotonated carboxylic group $\left(\mathrm{COO}^{-}\right)$in the side chain of Ty and L-Dopa is assigned to the reorganization of the monolayer while the catechol and $-\mathrm{NH}_{3}{ }^{+}$group play an important role in the packing degree of FePc. The increases in the packing degree of FePc in solution and of the Langmuir monolayer is influenced by the Fe-O and Fe-N coordination. The displacement to a smaller extrapolated area was also observed in Langmuir films obtained from FePc solution prepared in the different solvents $[16,18,26,27]$. The solvents DMF, DMSO, and DMA promoted the formation of FePc dimer in solution and also an increase in the molecular packing of Langmuir monolayer $[16,18,26,27]$. The authors ascribed this arrangement to the coordination of FePc with an oxygen or amine group present in the solvents $[16,18,26,27]$. Based on this, the higher effect observed on the packing of FePc on the Langmuir film at DA subphase can be ascribed to the presence of both catechol (oxygen atom) and amino group (nitrogen atom).

At $10^{-3} \mathrm{~mol} / \mathrm{L}$, the higher effect can also be ascribed to cyclic species once the DA showed a higher polymerization reactivity than L-Dopa [25]. This behavior is also observed by the $\pi$-A isotherm of FePc at Ep subphase (Figure 1D). The FePc $\pi$-A isotherm in the presence of $10^{-3} \mathrm{~mol} / \mathrm{L}$ Ep showed a higher displacement and a straight profile. In this case, color change in solution was observed before barrier compression, ascribed 
to fast Ep oxidation and polymerization in aqueous solution. The Ep showed a higher polymerization reactivity than DA and L-Dopa [25], which influenced the FePc packing on the monolayer. The Ep at lower concentrations $\left(10^{-5}\right.$ and $\left.10^{-4} \mathrm{~mol} / \mathrm{L}\right)$ showed similar displacement observed with L-Dopa (Figure 2). The principal difference in the Ep chemical structure is in the side chain, showing a hydroxyl group at 3-carbon-position and a secondary amine. Thus, the displacement observed in the FePc $\pi$-A isotherm in lower Ep concentration reinforces that both the catechol group and side-chain influence FePc packing and organization as Langmuir films.

The results from $\pi-\mathrm{A}$ isotherm showed that the chemical structure, charge, and concentration of catecholamine influence the organization and the packing degree of $\mathrm{FePc}$ monolayers. These slight differences can contribute to the development of sensors with a selectivity detection of these molecules. Thus, to reinforce the interaction described here, the FePc monolayer in the presence of catecholamines was transferred to $\mathrm{Ag}$ solid substrate as LS film and characterized by using SERS.

\subsection{SERS Analysis}

Monolayers of the FePc Langmuir film were deposited on Ag island substrates in the presence of respective catecholamines in the subphase $\left(10^{-4} \mathrm{~mol} / \mathrm{L}\right)$ for the spectral analysis at the molecular level. The SERS spectra obtained for FePc LS film deposited on Ag substrate (Figure 3) showed the characteristic bands ascribed to vibrational modes of the Pc macrocycle [16]. The main vibrational assignments of the SERS spectra of FePc film in $\mathrm{Ag}$ in the absence and presence of catecholamines EP, DA, LDA, and Ty are shown in Table 1. However, for the FePc LS/catecholamine films, new bands were observed in the 1300 to $1700 \mathrm{~cm}^{-1}$ wavenumber range. No changes were observed in the SERS spectra for $\mathrm{FePc}+\mathrm{Ty}$ film, in agreement with the $\pi$-A isotherm results. Thus, the Ty molecule interacts with the Langmuir monolayer, promoting a molecular reorganization but not complex or coordinated chemically with FePc molecules.

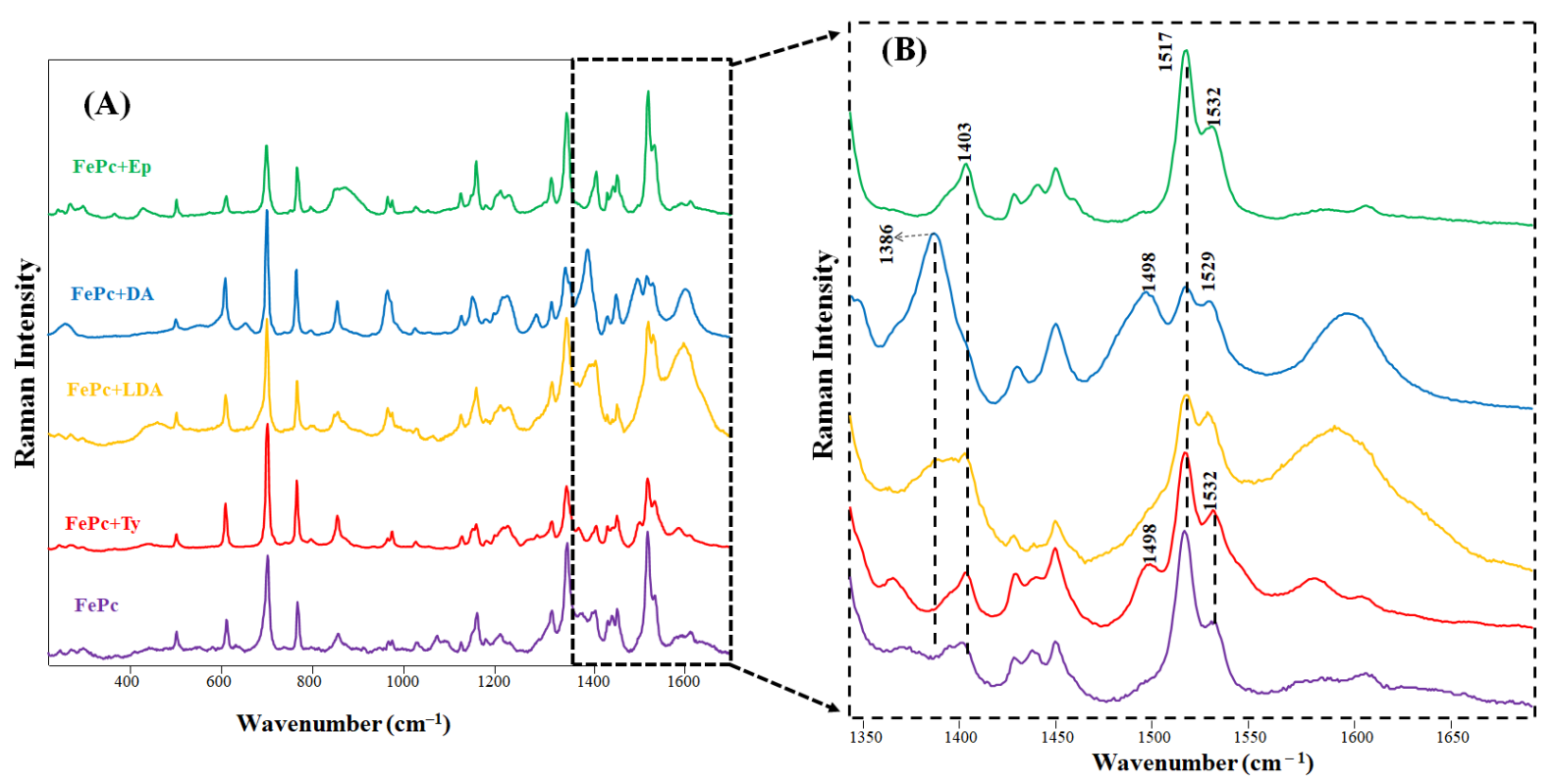

Figure 3. (A) SERS spectra obtained for FePc LS monolayer onto Ag substrate. The FePc LS monolayers were also deposited in the presence of Ty, L-Dopa, DA, and Ep $\left(10^{-4} \mathrm{~mol} / \mathrm{L}\right)$. (B) Magnification of the SERS spectra from 1300 to $1700 \mathrm{~cm}^{-1}$.

In the SERS spectra of FePc+L-Dopa and FePc+DA, a new band at $1386 \mathrm{~cm}^{-1}$ ascribed to $\mathrm{NH}_{2}$ antisymmetric deformation [28] and at $1498 \mathrm{~cm}^{-1}$ ascribed to a characteristic band from the catechol group, $v 19_{\mathrm{b}}$ (catechol ring breathing) $[29,30]$, were observed. The broadband c.a $1597 \mathrm{~cm}^{-1}$ is ascribed to C-C stretching, C-H in-plane bending from catechol ring [31], and 8a vibrational mode [32]. The new bands observed reinforce that L-Dopa 
and DA can interact through both the catechol group and amine group, an interaction also proposed from $\pi$-A isotherm results. The orientation, resultant of both catechol and amine group interaction, can also be observed in SERS measurements of L-Dopa and DA in Ag colloid [28,33]. Figueiredo et al. [28] reported that the catechol group showed higher reactivity and a metal-O bond with monoanionic catechol group formation after contact with metal surfaces. These results indicate an important role of the side chain in adsorption for DA SERS detection. Cao et al. [34] described DA and Ep detection using gold nanoparticles functionalized with Fe-NTA complexes, showing an intense band at $1481 \mathrm{~cm}^{-1}$ ascribed to $v 19_{\mathrm{b}}$ vibrational mode. Shi et al. [32] showed similar results for DA detection using the silver nanoparticles functionalized with Fe-NTA complexes, the $v 19_{b}$ vibrational mode observed at $1480 \mathrm{~cm}^{-1}$.

The band area decreases at $1517 \mathrm{~cm}^{-1}(45 \%$ in L-Dopa and $45 \%$ in DA) were ascribed to CNC stretching and C-H deformation from FePc macrocycle [28-30], suggesting that LDopa and DA interaction occur preferentially in the central coordination of FePc. The band at $1403 \mathrm{~cm}^{-1}$ (CNC stretching, pyrrole expansion, and $\mathrm{CH}$ in-plane bending) present in the FePc SERS spectra $[16,35,36]$ has vanished in the SERS spectra obtained to FePc+L-Dopa and $\mathrm{FePc}+\mathrm{DA}$, reinforcing interaction of these molecules at the FePc center, which makes it difficult to determine the vibrational mode's relation to Pc macrocycle.

Opposite to what was observed in the isotherm results, the SERS spectra from FePc+Ep film did not show any changes compared to the FePc spectra. This behavior can be ascribed to fast oxidation and polymerization of Ep in solution, which promotes important changes in the FePc organization as the Langmuir monolayer. However, the interaction is weak, as observed in the presence of Ty. Thus, we conclude that catechol $+\mathrm{NH}_{3}{ }^{+}$(from side chain) plays an essential role in coordinating FePc.

Table 1. Vibrational assignments of the SERS spectra collected to LS FePc film deposited ontoAg in absence and presence of catecholamines EP, DA, LDA, and Ty.

\begin{tabular}{rccccr}
\hline FePc & FePc+EP & FePc+DA & FePc+LDA & FePc+Ty & Assignments \\
\hline & - & 1386 & - & - & $\begin{array}{c}\mathrm{NH}_{2} \text { antisymmetric deformation [28], } \\
\text { C-H } \mathrm{H}_{2} \text { torcion and bending [37] }\end{array}$ \\
\hline 1403 & 1403 & - & 1403 & 1403 & CNC stretching, pyrrole expansion, and CH in-plane bending [16] \\
\hline 1429 & 1429 & 1429 & 1429 & 1429 & $\mathrm{CH}_{2}$ in-plane deformation [28] \\
\hline 1450 & 1450 & 1450 & 1450 & 1450 & $\begin{array}{c}\text { C-O-H in-plane deformation, } \\
\text { C-C stretching [37] }\end{array}$ \\
\hline & -1498 & - & 1498 & $\begin{array}{c}\text { C-C stretching + C-H in-plane deformation mode + C-OH stretching } \\
\text { [38] }\end{array}$ \\
\hline 1517 & 1517 & 1517 & 1517 & 1517 & CNC stretching and C-H deformation [28,29] \\
\hline 1532 & 1532 & 1529 & 1529 & & Stretching of the catechol group [28,29] \\
\hline
\end{tabular}

The same interaction pattern observed in the SERS spectra of Figure 3 was visualized through a multidimensional projection, normalized IDMAP (Figure 4). In this case, each point corresponds to one SERS spectrum of FePc and FePc/catecholamine LS films. Clusters are similar by distance-the farther apart from each other, the greater the interaction. The $\mathrm{FePc}+\mathrm{Ty}$ and FePc+Ep SERS spectra cluster are closer to the FePc SERS spectra cluster in the projection. The cluster of $\mathrm{FePc}+\mathrm{DA}$ and $\mathrm{FePc}+\mathrm{L}$-Dopa SERS spectra showed the greatest distance, indicating greater changes concerning the FePc SERS spectrum. These results reinforce that of the studied molecules, L-Dopa and DA have greater interactions/coordination with FePc. 


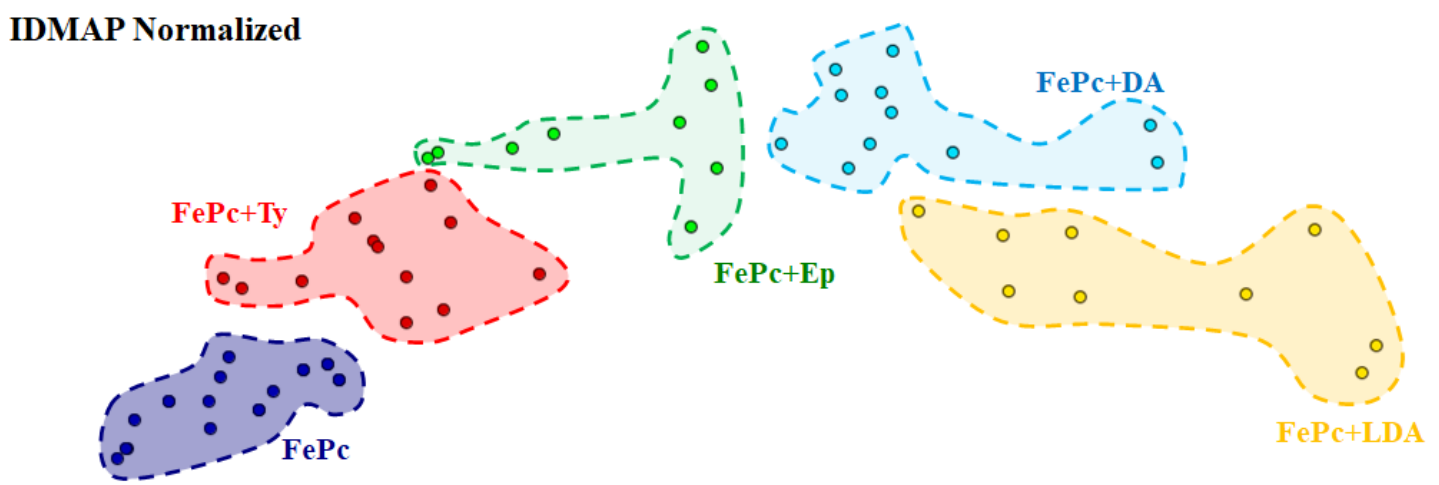

Figure 4. IDMAP multidimensional projection normalized grouping the results for different SERS spectra collected for the FePc LS films deposited in the absence and presence of Ty, L-Dopa, DA, and Ep onto Ag substrate. Each dot represents one SERS spectra collected between 200 and $4000 \mathrm{~cm}^{-1}$. The dashed circle with several points inside represents the SERS spectra grouped by similarity.

\subsection{Electrochemical Measurements}

Interaction of catecholamines and FePc effects on electrochemical detection was evaluated using the ITO electrode modified with 20 LS layers of FePc. Potential cycles of the FePc LS films were performed in the absence and presence of catecholamines at $1.2 \times 10^{-4} \mathrm{~mol} / \mathrm{L}$ (Figure 5). The FePc LS films showed a quasi-reversible process at Epa $=-530$ and Epc $=-800 \mathrm{mV}$ ascribed to oxidation and reduction of FePc [39]. Catecholamines changed the FePc redox process and created an irreversible oxidation peak ascribed to oxidation of catechol groups (except for Ty) [40]. The catechol group generally shows a reversible peak ascribed to the catechol/quinone redox couple [41]. However, in this case, the catecholamine (L-Dopa, DA, and Ep) interaction at FePc LS film surface promoted irreversible catechol oxidation due to adsorption of molecules on the film surface after the first anodic potential cycle. The irreversibility was observed only after the second potential cycle [11]. The anodic peak potential showed a shift to more positive values from DA $>$ L-Dopa>Ep (190, 201, and $215 \mathrm{mV}$, respectively). Thus, once all the catecholamines studied showed the same catechol group, the changes in the potential redox values suggest that the catechol group and the amine chain influence adsorption/interaction of catecholamines at the FePc film surface.
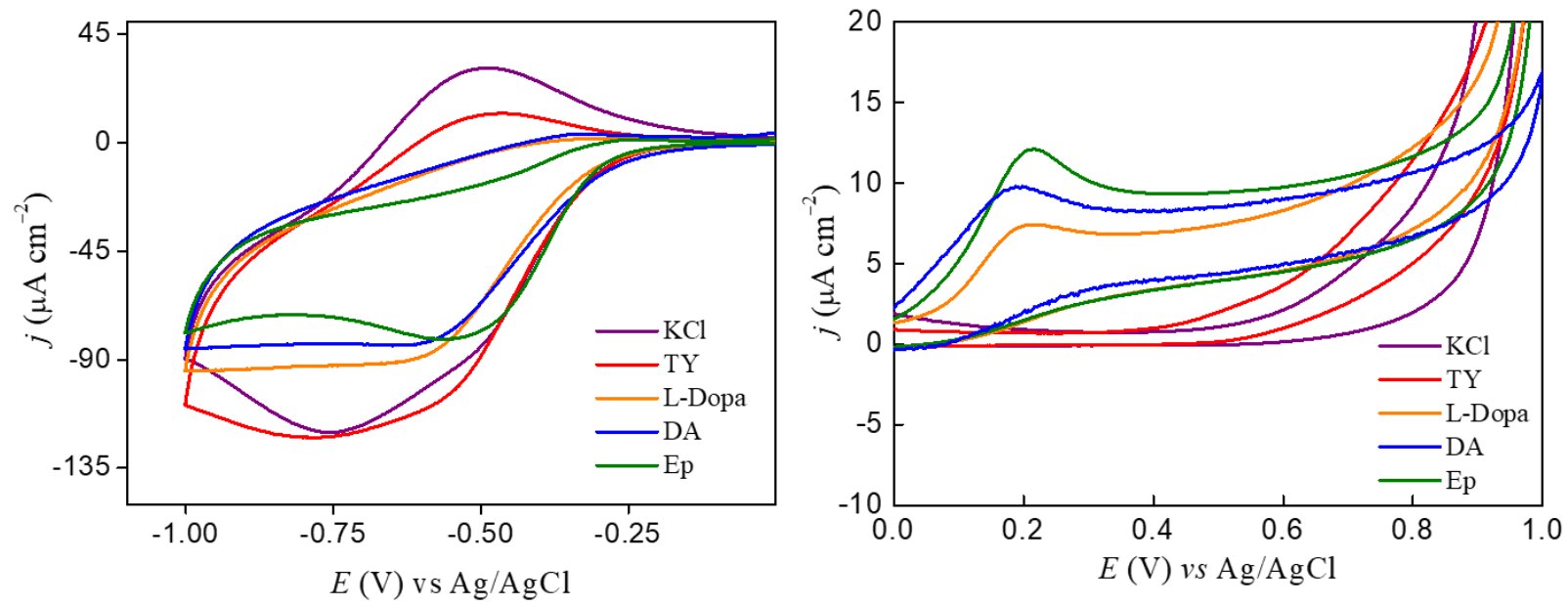

Figure 5. Cyclic voltammogram for FePc LS film in $\mathrm{KCl}$ and the presence of $2.4 \times 10^{-4} \mathrm{~mol} / \mathrm{L}$ of catecholamines Ty, L-Dopa, $\mathrm{DA}$, and $\mathrm{Ep},(\mathrm{A})$ in the potential range from 0 to $-1 \mathrm{~V}$ vs. $\mathrm{Ag} / \mathrm{AgCl}$, and (B) magnification of cyclic voltammogram in the potential range 0 to $1 \mathrm{~V}$ vs. $\mathrm{Ag} / \mathrm{AgCl} . v=50 \mathrm{mV} / \mathrm{s}$. 
The influence of both sides of catecholamine (catechol and amino groups) in the interaction with the FePc film surface can be observed by decreasing the FePc redox process at negative potential. The smaller changes were observed in the Ty solution, suggesting a weak interaction with the FePc film surface, even under successive cyclic potential ranges. In a platinum electrode, the tyrosine oxidized at a potential higher than $1.0 \mathrm{~V}$ and the presence of molecular oxygen made it be adsorbed onto the electrode surface through the carboxylic and phenol groups as described by Ogura et al. [42]. Enche et al. [43] also described the dependence of molecular oxygen in solution and the adsorption of Ty onto a glassy carbon electrode, which is pH-medium-dependent [43]. However, in our case, the weak interaction between FePc and Ty makes difficult the electron transfer to phenol oxidation at a potential lower than $1.0 \mathrm{~V}$. On the other hand, the L-Dopa showed a higher current decrease of the FePc redox process than Ty, supporting that the presence of a catechol group can have a significant influence once L-Dopa shows the same side chain of the Ty. The Ty also showed less interaction with FePc molecules from Langmuir and SERS measurements, reinforcing that molecules with catechol groups can influence more than phenol groups (Ty in this case).

The L-Dopa and DA showed a similar effect on the peak current of the FePc redox process. This effect can be ascribed to the adsorption of the catechol group and interaction through $-\mathrm{NH}_{3}{ }^{+}$group, once the $\mathrm{N}$ atom also showed an interaction with iron metal as described above. However, the DA showed a higher catechol peak current and a smaller anodic redox potential than L-Dopa, indicating that adsorption in the FePc film is favored by both the catechol group and $-\mathrm{NH}_{3}{ }^{+}$group, but the carboxyl group from L-Dopa can affect the interaction through the side chain. This result agrees with the displacement observed in Langmuir films, in which DA showed a higher displacement at all concentrations evaluated than L-Dopa. In addition, the SERS and IDMAP projection also showed a similar effect of L-Dopa and DA, ascribed to structure effect. The adsorption process was investigated through potential cycles in supporting electrolytes after analysis in L-Dopa. The anodic peak current values were linear with the scan rate (Figure 6A), indicating a surface process (adsorptive process), which reinforces the hypothesis that adsorption of L-Dopa occurs on the FePc film surface.

In the case of Ep, the presence of the methyl radical at the end of the side chain can reduce the adsorption process on the film surface. Still, it facilitates the process of electron transfer from the catechol group to the electrode surface. This effect can be observed through higher intensities of oxidation current of the catechol group obtained in the presence of Ep.

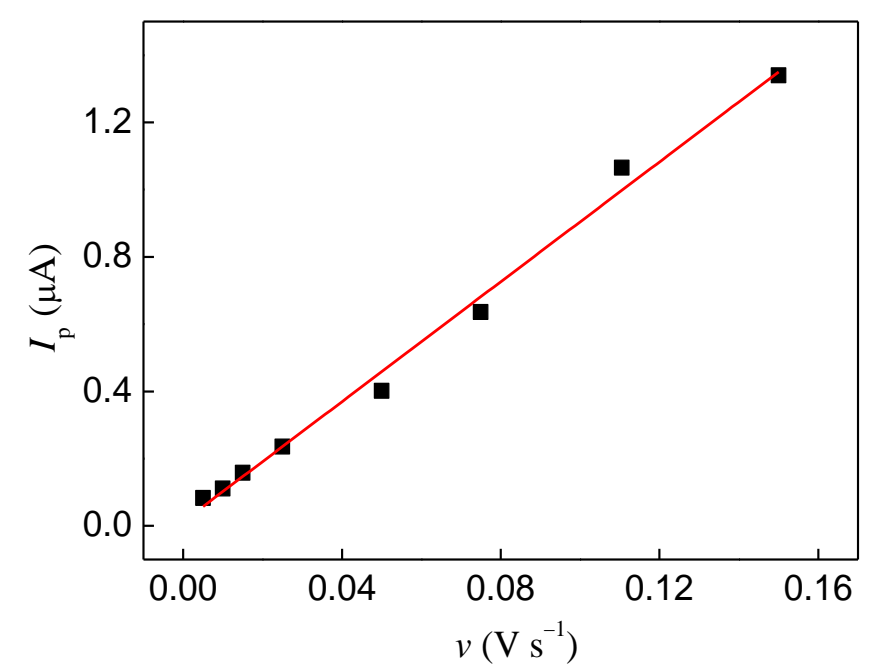

Figure 6. Variation of the anodic current peak with a scan rate of FePc LS films in $\mathrm{KCl} 0.1 \mathrm{~mol} / \mathrm{L}$ after successive potential cycles in the presence of $1.2 \times 10^{-4} \mathrm{~mol} / \mathrm{L} \mathrm{L}-\mathrm{Dopa}$. 


\subsection{Application in Drug Samples}

The FePc LS film was applied as a sensor to detect L-Dopa in a commercial tablet used in Parkinson's disease. Thus, the interfering study was carried out using the active electrochemical compound present in this drug. The commercial tablet used here comprises $200 \mathrm{mg}$ of L-Dopa and $50 \mathrm{mg}$ of benserazide hydrochloride per tablet $(250 \mathrm{mg}$ of active compound). Cyclic voltammetry was performed in 1:1 and 4:1 ( $\mathrm{mol} / \mathrm{mol})$ of L-Dopa and benserazide and $2.4 \times 10^{-4} \mathrm{~mol} / \mathrm{L}$ benserazide (Figure 7A). In benserazide (standard), a minimal redox process at ca. $240 \mathrm{mV}$ was observed, ascribed to the oxidation of the pyrogallol group [44]. The benserazide showed a significant difference in molecular structure (Figure 7B), and the side chain showed amino, amide, and hydroxyl groups, which provide more than one coordination site. This behavior reinforces the effect of the side chain of the molecule's structure on the FePc surface coordination/adsorption. Due to both L-Dopa and benserazide adsorption, a significant decrease of the peak current was observed in both mixtures of L-Dopa+benserazide (Figure 7C), showing interference of c.a $45 \%$.
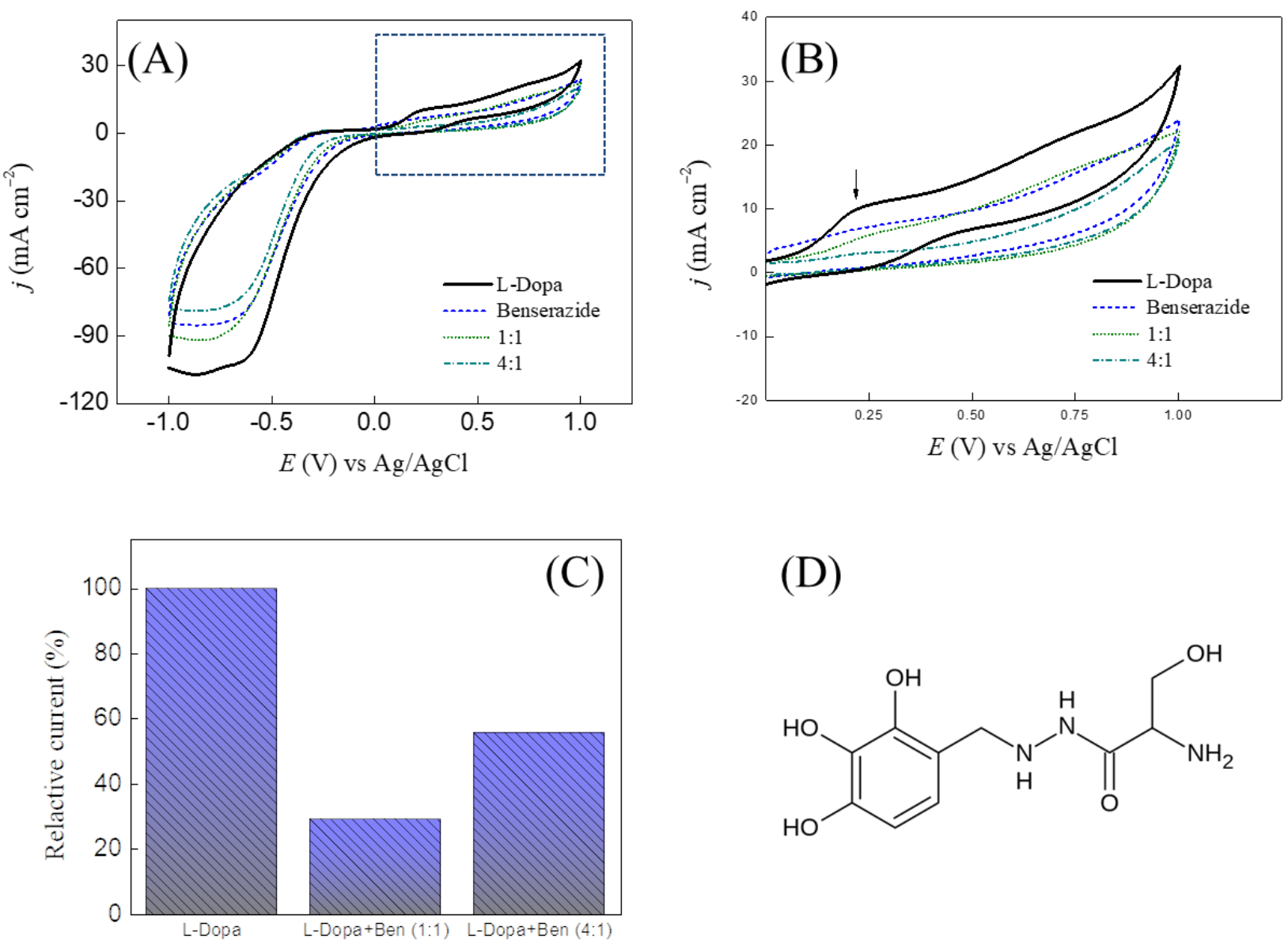

(D)<smiles>NC(CO)C(=O)NNCc1ccc(O)c(O)c1O</smiles>

Figure 7. (A) Cyclic voltammogram for FePc LS film in the presence of $2.4 \times 10^{-4} \mathrm{~mol} / \mathrm{L}$ of L-Dopa, benserazide, and their mixture in molar ratio 1:1 and 4:1 (L-Dopa: benserazide). $v=50 \mathrm{mV} / \mathrm{s}$. (B) Magnification of potential range from 0 to $+1 \mathrm{~V}$ vs. $\mathrm{Ag} / \mathrm{AgCl}$. (C) The relative current ratio for detecting L-Dopa in the presence of benserazide. Relative Current = [anodic peak current of L-Dopa+benserazide/peak current L-Dopa] ×100). (D) Chemical structure of benserazide.

The FePc LS film was thus evaluated as a sensor for detecting bioactive compounds in commercial drug samples (L-Dopa+benserazide in this case) using the standard addition. The analysis showed a concentration of $240 \pm 44 \mathrm{mg}$, which is close to the amount of bioactive compound indicated by the manufacturer ( $200 \mathrm{mg}$ L-Dopa and $50 \mathrm{mg}$ benserazide). It is important to report that drug sample preparation influenced the result (low and room temperature). In our case, we considered the sample preparation in the ice bath: once at 
room temperature, a color change ascribed to oxidation and polyphenol polymerization was observed. The sample prepared in the ice bath was obtained with a uniform content of $96 \pm 18 \%$, while at a room temperature of $89 \pm 25 \%$, was ascribed to a decrease of free polyphenol and an increase of cycle (or polymeric) form.

The development of electrochemical sensors for the simultaneous determination of LDopa and benserazide in drug samples has been reported [44-47]. Zapata-Urzúa et al. [47] reported the application of an unmodified glassy carbon electrode for the determination of L-Dopa and benserazide in the same commercial brand of drug samples, with the same bioactive compound used in our study, obtaining a uniformity of content of $103.2 \pm 1.1$ and $96.1 \pm 0.7 \%$, when using the L-Dopa or benserazide as standard, respectively. Thus, based on our results, FePc LS thin films can be widely applied as a sensor to determine bioactive compounds/catecholamines in drug samples. However, the sample opening methodology should be better investigated to possibly increase the selectivity of the applied sensors.

\section{Conclusions}

Through in situ analysis performed in Langmuir films and characterization at the molecular level using the SERS technique, we observe that the catechol group and the protonated amino group can coordinate with the iron metal center of FePc. Thus, the LDopa and DA were the catecholamine molecules that showed higher adsorption at the FePc film surface, promoting a decrease of oxidation potential. The adsorption of the catechol group enables the irreversibility of the catechol redox couple, but the side chain is related to the sensibility of the electrochemical sensor. Thus, the specific coordination of catechol and protonated amino group on the iron metal center from FePc plays an essential role in the electrochemical detection of catecholamines. The FePc LS films showed significant application as a sensor for L-Dopa detection in drug samples, with a uniformity of content of $96 \%$.

Author Contributions: Conceptualization, C.S.M.; methodology, C.S.M.; formal analysis, C.S.M., R.J.G.R. and J.N.S.; investigation, C.S.M., R.J.G.R. and J.N.S.; resources, C.S.M. and P.A.; data curation, C.S.M., R.J.G.R., J.N.S. and P.A.; writing-original draft preparation, C.S.M., R.J.G.R., J.N.S. and P.A.; writing-review and editing, C.S.M. and P.A.; visualization, C.S.M. and P.A.; supervision, P.A.; project administration, P.A. funding acquisition, C.S.M. and P.A. All authors have read and agreed to the published version of the manuscript.

Funding: This research was funded by FAPESP (2018/22214-6, 2017/06534-8, 2017/15019-0, 2020/05423-0), CNPq (422163/2018-0 and 304836/2018-4), CAPES, and National Institute for Science and Technology on Organic Electronics (INEO) (CNPq process number 465572/2014-6, FAPESP 2014/50869-6, and CAPES 23038.000776/201754).

Institutional Review Board Statement: Not applicable.

Informed Consent Statement: Not applicable.

Acknowledgments: This work was financially supported by FAPESP (2018/22214-6, 2017/06534-8, 2017/15019-0, 2020/05423-0), CNPq (422163/2018-0 and 304836/2018-4), CAPES, and National Institute for Science and Technology on Organic Electronics (INEO) (CNPq process number 465572/2014-6, FAPESP 2014/50869-6, and CAPES 23038.000776/201754).

Conflicts of Interest: The authors declare no conflict of interest.

\section{References}

1. Deng, Y.-H.; Wang, H.; Zhang, H.-S. Determination of amino acid neurotransmitters in human cerebrospinal fluid and saliva by capillary electrophoresis with laser-induced fluorescence detection. J. Sep. Sci. 2008, 31, 3088-3097. [CrossRef]

2. Thomas Broome, S.; Louangaphay, K.; Keay, K.; Leggio, G.; Musumeci, G.; Castorina, A. Dopamine: An immune transmitter. Neural Regen. Res. 2020, 15, 2173. [CrossRef] [PubMed]

3. Pan, X.; Kaminga, A.C.; Jia, P.; Wen, S.W.; Acheampong, K.; Liu, A. Catecholamines in Alzheimer's Disease: A Systematic Review and Meta-Analysis. Front. Aging Neurosci. 2020, 12. [CrossRef]

4. Sarkar, C.; Basu, B.; Chakroborty, D.; Dasgupta, P.S.; Basu, S. The immunoregulatory role of dopamine: An update. Brain. Behav. Immun. 2010, 24, 525-528. [CrossRef] 
5. Hašková, P.; Koubková, L.; Vávrová, A.; Macková, E.; Hrušková, K.; Kovaříková, P.; Vávrová, K.; Šimůnek, T. Comparison of various iron chelators used in clinical practice as protecting agents against catecholamine-induced oxidative injury and cardiotoxicity. Toxicology 2011, 289, 122-131. [CrossRef] [PubMed]

6. Oni, J.; Nyokong, T. Interaction between iron(II) tetrasulfophthalocyanine and the neurotransmitters, serotonin and dopamine. Polyhedron 2000, 19, 1355-1361. [CrossRef]

7. Sundar, S.; Venkatachalam, G.; Kwon, S. Sol-Gel Mediated Greener Synthesis of $\gamma$ - $\mathrm{Fe}_{2} \mathrm{O}_{3}$ Nanostructures for the Selective and Sensitive Determination of Uric Acid and Dopamine. Catalysts 2018, 8, 512. [CrossRef]

8. Ranku, M.N.; Uwaya, G.E.; Fayemi, O.E. Electrochemical Detection of Dopamine at $\mathrm{Fe}_{3} \mathrm{O}_{4} /$ SPEEK Modified Electrode. Molecules 2021, 26, 5357. [CrossRef]

9. Fan, Z.; Wang, M.; Wu, S.; Wang, H.; Li, J.; Liu, L.; Rong, J.; Tong, Z.; Zhang, X. A novel nanotube based on self-assembled iron porphyrin/tantalum tungstate composite for electrochemical detection of dopamine. J. Mater. Sci. 2020, 55, 7833-7842. [CrossRef]

10. Wang, H.; Cao, T.; Wu, S.; Wang, S.; Yan, C.; Wang, Z.; Zhang, X.; Tong, Z. Synthesis of Novel Iron Porphyrin/Titanoniobate Nanocomposite for Electrochemical Detection of Uric Acid. J. Electrochem. Soc. 2021, 168, 077509. [CrossRef]

11. Martin, C.S.; Alessio, P.; Crespilho, F.N.; Brett, C.M.A.; Constantino, C.J.L. Influence of the supramolecular arrangement of iron phthalocyanine thin films on catecholamine oxidation. J. Electroanal. Chem. 2019, 836, 7-15. [CrossRef]

12. Martin, C.S.; Gouveia-Caridade, C.; Crespilho, F.N.; Constantino, C.J.L.; Brett, C.M.A. Iron Phthalocyanine Electrodeposited Films: Characterization and Influence on Dopamine Oxidation. J. Phys. Chem. C 2016, 120, 15698-15706. [CrossRef]

13. Keshavananda Prabhu, C.P.; Nemakal, M.; Aralekallu, S.; Mohammed, I.; Palanna, M.; Sajjan, V.A.; Akshitha, D.; Sannegowda, L.K. A comparative study of carboxylic acid and benzimidazole phthalocyanines and their surface modification for dopamine sensing. J. Electroanal. Chem. 2019, 847, 113262. [CrossRef]

14. Andersen, A.; Chen, Y.; Birkedal, H. Bioinspired Metal-Polyphenol Materials: Self-Healing and Beyond. Biomimetics 2019, 4, 30. [CrossRef] [PubMed]

15. Chen, K.; Liu, K.; An, P.; Li, H.; Lin, Y.; Hu, J.; Jia, C.; Fu, J.; Li, H.; Liu, H.; et al. Iron phthalocyanine with coordination induced electronic localization to boost oxygen reduction reaction. Nat. Commun. 2020, 11, 4173. [CrossRef]

16. Alessio, P.; Rodríguez-Méndez, M.L.; De Saja Saez, J.A.; Constantino, C.J.L. Iron phthalocyanine in non-aqueous medium forming layer-by-layer films: Growth mechanism, molecular architecture and applications. Phys. Chem. Chem. Phys. 2010, 12, 3972-3983. [CrossRef]

17. Coates, M.; Nyokong, T. Characterization of glassy carbon electrodes modified with carbon nanotubes and iron phthalocyanine through grafting and click chemistry. Electrochim. Acta 2013, 91, 158-165. [CrossRef]

18. Rubira, R.J.G.; Aoki, P.H.B.; Constantino, C.J.L.; Alessio, P. Supramolecular architectures of iron phthalocyanine LangmuirBlodgett films: The role played by the solution solvents. Appl. Surf. Sci. 2017, 416, 482-491. [CrossRef]

19. Alessio, P.; Pavinatto, F.J.; Oliveira, O.N., Jr.; De Saja Saez, J.A.; Constantino, C.J.L.; Rodríguez-Méndez, M.L. Detection of catechol using mixed Langmuir-Blodgett films of a phospholipid and phthalocyanines as voltammetric sensors. Analyst 2010, $135,2591$. [CrossRef]

20. Phan, M.D.; Lee, J.; Shin, K. Collapsed States of Langmuir Monolayers. J. Oleo Sci. 2016, 65, 385-397. [CrossRef]

21. Jiao, T.; Xing, R.; Zhang, Q.; Lv, Y.; Zhou, J.; Gao, F. Self-Assembly, Interfacial Nanostructure, and Supramolecular Chirality of the Langmuir-Blodgett Films of Some Schiff Base Derivatives without Alkyl Chain. J. Nanomater. 2013, 2013, 1-9. [CrossRef]

22. Zhang, Q.; Jin, B.; Wang, X.; Lei, S.; Shi, Z.; Zhao, J.; Liu, Q.; Peng, R. The mono(catecholamine) derivatives as iron chelators: Synthesis, solution thermodynamic stability and antioxidant properties research. R. Soc. Open Sci. 2018, 5, 171492. [CrossRef] [PubMed]

23. Dreyer, D.R.; Miller, D.J.; Freeman, B.D.; Paul, D.R.; Bielawski, C.W. Elucidating the Structure of Poly(dopamine). Langmuir 2012, 28, 6428-6435. [CrossRef]

24. Petran, A.; Mrówczyński, R.; Filip, C.; Turcu, R.; Liebscher, J. Melanin-like polydopa amides-Synthesis and application in functionalization of magnetic nanoparticles. Polym. Chem. 2015, 6, 2139-2149. [CrossRef]

25. Sugumaran, M. Reactivities of Quinone Methides versus o-Quinones in Catecholamine Metabolism and Eumelanin Biosynthesis. Int. J. Mol. Sci. 2016, 17, 1576. [CrossRef]

26. Zucolotto, V.; Ferreira, M.; Cordeiro, M.R.; Constantino, C.J.L.; Balogh, D.T.; Zanatta, A.R.; Moreira, W.C.; Oliveira, O.N. Unusual interactions binding iron tetrasulfonated phthalocyanine and poly(allylamine hydrochloride) in layer-by-layer films. J. Phys. Chem. B 2003, 107, 3733-3737. [CrossRef]

27. Wöhrle, D. Phthalocyanines: Properties and Applications; Leznoff, C.C., Lever, A.B.P., Weinheim, V.C.H., Eds.; Available online: https:/ / onlinelibrary.wiley.com/doi/abs/10.1002/adma.19930051217 (accessed on 1 November 2021). [CrossRef]

28. Figueiredo, M.L.B.; Martin, C.S.; Furini, L.N.; Rubira, R.J.G.; Batagin-Neto, A.; Alessio, P.; Constantino, C.J.L. Surface-enhanced Raman scattering for dopamine in Ag colloid: Adsorption mechanism and detection in the presence of interfering species. Appl. Surf. Sci. 2020, 522, 146466. [CrossRef]

29. Qin, L.; Li, X.; Kang, S.Z.; Mu, J. Gold nanoparticles conjugated dopamine as sensing platform for SERS detection. Colloids Surf. B Biointerfaces 2015, 126, 210-216. [CrossRef] [PubMed]

30. Youn, M.Y.; Kim, Y.; Lee, N.S. Raman Spectroscopic Study of Monodentate Dopamine Adsorbed on Silver and Copper Adatoms. Bull. Korean Chem. Soc. 1997, 18, 1314-1316. 
31. Feng, J.; Fan, H.; Zha, D.; Wang, L.; Jin, Z. Characterizations of the Formation of Polydopamine-Coated Halloysite Nanotubes in Various pH Environments. Langmuir 2016, 32, 10377-10386. [CrossRef]

32. Shi, C.-X.; Chen, Z.-P.; Chen, Y.; Liu, Q.; Yu, R.-Q. Quantification of dopamine in biological samples by surface-enhanced Raman spectroscopy: Comparison of different calibration models. Chemom. Intell. Lab. Syst. 2017, 169, 87-93. [CrossRef]

33. Rubira, R.J.G.; Camacho, S.A.; Martin, C.S.; Mejía-Salazar, J.R.; Gómez, F.R.; da Silva, R.R.; de Oliveira Junior, O.N.; Alessio, P.; Constantino, C.J.L. Designing silver nanoparticles for detecting levodopa (3,4-dihydroxyphenylalanine, 1-dopa) using surfaceenhanced raman scattering (SERS). Sensors 2020, 20, 15. [CrossRef]

34. Cao, X.; Qin, M.; Li, P.; Zhou, B.; Tang, X.; Ge, M.; Yang, L.; Liu, J. Probing catecholamine neurotransmitters based on ironcoordination surface-enhanced resonance Raman spectroscopy label. Sens. Actuators B Chem. 2018, 268, 350-358. [CrossRef]

35. Aroca, R.; Thedchanamoorthy, A. Vibrational Studies of Molecular Organization in Evaporated Phthalocyanine Thin Solid Films. Chem. Mater. 1995, 7, 69-74. [CrossRef]

36. Liu, Z.; Zhang, X.; Zhang, Y.; Jiang, J. Theoretical investigation of the molecular, electronic structures and vibrational spectra of a series of first transition metal phthalocyanines. Spectrochim. Acta Part A Mol. Biomol. Spectrosc. 2007, 67, 1232-1246. [CrossRef]

37. Park, S.K.; Lee, C.K.; Lee, S.H.; Lee, N.S. Vibrational analysis of ferrocyanide complex ion based on density functional force field. Bull. Korean Chem. Soc. 2002, 23, 253-261. [CrossRef]

38. Jha, O.; Yadav, T.K.; Yadav, R.A. Structural and vibrational study of a neurotransmitter molecule: Dopamine [4-(2-aminoethyl) benzene-1,2-diol]. Spectrochim. Acta Part A Mol. Biomol. Spectrosc. 2018, 189, 473-484. [CrossRef] [PubMed]

39. Martin, C.S.; Alessio, P.; Crespilho, F.N.; Constantino, C.J.L. Supramolecular Arrangement of Iron Phthalocyanine in LangmuirSchaefer and Electrodeposited Thin Films. J. Nanosci. Nanotechnol. 2018, 18, 3206-3217. [CrossRef]

40. Cheng, H.; Qiu, H.; Zhu, Z.; Li, M.; Shi, Z. Investigation of the electrochemical behavior of dopamine at electrodes modified with ferrocene-filled double-walled carbon nanotubes. Electrochim. Acta 2012, 63, 83-88. [CrossRef]

41. Martin, C.S.; Alessio, P. Analysis of Polyphenolic Content in Teas Using Sensors. In Safety Issues in Beverage Production; Elsevier: Amsterdam, The Netherlands, 2020; pp. 359-397.

42. Ogura, K.; Kobayashi, M.; Nakayama, M.; Miho, Y. In-situ FTIR studies on the electrochemical oxidation of histidine and tyrosine. J. Electroanal. Chem. 1999, 463, 218-223. [CrossRef]

43. Enache, T.A.; Oliveira-Brett, A.M. Phenol and para-substituted phenols electrochemical oxidation pathways. J. Electroanal. Chem. 2011, 655, 9-16. [CrossRef]

44. Pérez-Ortiz, M.; Bollo, S.; Zapata-Urzúa, C.; Yáñez, C.; Álvarez-Lueje, A. Voltammetric study and direct analytical determination of the antiparkinson drug benserazide. Anal. Lett. 2011, 44, 1683-1698. [CrossRef]

45. Wang, J.; Zhou, Y.; Liang, J.; He, P.G.; Fang, Y.Z. Determination of Levodopa and Benserazide Hydrochloride in Pharmaceutical Formulations by CZE with Amperometric Detection. Chromatographia 2005, 61, 265-270. [CrossRef]

46. Ensafi, A.A.; Arabzadeh, A.; Karimi-Maleh, H. Sequential determination of benserazide and levodopa by voltammetric method using chloranil as a mediator. J. Braz. Chem. Soc. 2010, 21, 1572-1580. [CrossRef]

47. Zapata-Urzúa, C.; Pérez-Ortiz, M.; Bravo, M.; Olivieri, A.C.; Álvarez-Lueje, A. Simultaneous voltammetric determination of levodopa, carbidopa and benserazide in pharmaceuticals using multivariate calibration. Talanta 2010, 82, 962-968. [CrossRef] [PubMed] 